\title{
Maternal and perinatal outcome in meconium stained amniotic fluid at term: a case control study
}

\author{
Dhana Priya Samiyappa*, Seetesh Ghose, Lopamudra B. John, Rupal Samal
}

\begin{abstract}
Department of Obstetrics and Gynaecology, Mahatma Gandhi Medical College and Research Institute, Puducherry,
\end{abstract} India

Received: 19 January 2016

Revised: 10 September 2016

Accepted: 12 September 2016

\author{
*Correspondence: \\ Dr. Dhana Priya Samiyappa, \\ E-mail: drdhanapriyamgmc@gmail.com
}

Copyright: (c) the author(s), publisher and licensee Medip Academy. This is an open-access article distributed under the terms of the Creative Commons Attribution Non-Commercial License, which permits unrestricted non-commercial use, distribution, and reproduction in any medium, provided the original work is properly cited.

\begin{abstract}
Background: Fetal well-being has traditionally been evaluated on the basis of fetal activity, FHR and presence of meconium in liquor in vertex presentation. Passage of meconium is considered physiological sign of fetal maturity on one hand and a sign of fetal distress and response to hypoxic insult on the other hand.

Methods: Pregnant women of 37 - 42weeks gestation with singleton pregnancy and cephalic presentation admitted in labour ward of Mahatma Gandhi Medical College and Research Institute with clear or meconium stained amniotic fluid following spontaneous rupture or ARM were included in the study. Outcome measures were fetal heart rate abnormality, mode of delivery, Apgar score, NICU admission and diagnosis of MAS.

Results: A total of 678 pregnant women were studied. Of them 226 had meconium stained and taken as study group. Rest 452 served as control group. The average gestational age of study group was $39.26 \pm 0.81$. Abnormal FHR was observed in $56 \%$.Spontaneous vaginal delivery was observed in $27.9 \%$ cases, instrumental delivery in $21.2 \%$ and caesarean section was $50.9 \%$ cases. Rate of low Apgar score $4.4 \%$ and it was two times higher in study group. NICU admission was observed in $46.7 \%$ cases of exposed group. Incidence of MAS in our study was $1.3 \%$.

Conclusions: In low resource settings where fetal scalp $\mathrm{pH}$, and umbilical card lactate estimation facilities are not available, association of MSL with abnormal FHR can be taken as fetal distress and hence consideration of early operative intervention is necessary.
\end{abstract}

Keywords: Meconium stained liquor, Maternal outcome, Perinatal outcome

\section{INTRODUCTION}

Fetal assessment and wellbeing has traditionally been evaluated on the basis of FHR patterns, fetal movements and colour of the amniotic fluid. Presence of meconium in the amniotic fluid has long been considered as ominous sign for fetal distress, although the exact cause is not known, passage of meconium is considered as physiological maturity of fetus. ${ }^{1,2}$

Meconium reduces the antibacterial property of amniotic fluid by altering the level of zinc in it which leads to intra amniotic infections. In case of hypoxia, gasping of fetus results in meconium aspiration which neutralizes the surfactant action and promotes inflammation of lung tissues, whereas persistent hypoxia after birth, aspirated meconium results in pulmonary vascular and pulmonary hypertension.

Conflicting outcomes have been reported in the deliveries complicated by meconium staining, which differs with the degree of meconium staining. ${ }^{3}$

MSAF is one of the reasons for increase in operative deliveries. ${ }^{1}$ The incidence of meconium staining has remained approximately $12 \%$ since last century. Yoder 
reported a nearly 4 fold decrease in MAS incidence from 1990-1992 to 1997-1998, as a result of early induction of labour, early amniotomy, use of amnioinfusion in some cases and increased caesarean section rate. Presence of meconium below the vocal cord is known as meconium aspiration syndrome. ${ }^{4}$ As per previous studies, only $5 \%$ of neonates born through meconium stained amniotic fluid develop MAS. ${ }^{4}$

Many studies suggest that MSAF is low risk obstetrical hazard because the perinatal mortality rate attributable to meconium was 1 death per 1000 live birth Many researchers have disregarded the importance of MSAF as an indicator of fetal distress. However a significant association has been reported between the consistency of meconium and abnormal FHR patterns, increased rate of caesarean section and low Apgar scores. 1,5

Although the direct and indirect effects of meconium staining remain uncertain, MSAF is considered as a predictor of maternal and perinatal morbidity and mortality. ${ }^{2}$ The present study was carried out to find out the maternal and perinatal outcome associated with meconium stained liquor in our institution.

The objectives of the study was to estimate the prevalence and mode of delivery and maternal and perinatal morbidity associated with meconium stained amniotic fluid at term.

\section{METHODS}

The present study was conducted in Mahatma Gandhi Medical College and Research Institute Hospital, Pondicherry, a rural tertiary care centre between November 2013 - April 2015. During this study period patient who had MSL on spontaneous or artificial rupture of membrane comprised the study group and those with clear liquor comprised control group. Cases with meconium stained liquor was graded as thick and thin MSL. Pregnant women with MSL were monitored continuously with CTG.

- "Thick" if the fluid is, dark green in colour, viscous, tenacious and containing large amount of particulate material

- "Thin" if the fluid is lightly stained without particulate material

Intrapartum cardiotocographic tracing also taken for assessing fetal hypoxia during labour where in the present study bradycardia was considered when fetal heart rate below $110 \mathrm{bpm}$ and tachycardia when fetal heart rate above $160 \mathrm{bpm}$.Apgar score of the newborn was assessed at 1 minute. Babies were considered nonasphyxiated and good condition when Apgar score was 7 or more. Babies were considered moderately asphyxiated when score was between 4 to 6 and was considered grossly asphyxiated when score was below 4 . Resuscitation was considered according to need determined by Apgar scoring in consultation with neonatologist.

Follow-up of the newborn

Babies with Apgar $>6$ placed with the mother. Babies with Apgar <5 were transferred to NICU for observation. Babies who developed any sign of complications within 24 hours were kept in NICU.

\section{Sample size}

This study comprised a sample size of 226 pregnant women which was calculated from

$\mathrm{n}=4 \mathrm{pq} / 12$ considering prevalence of meconium stained liquor as $18 \%$ from previous literature ,allowable error as $5 \%$ and confidence interval as $95 \%$. To prevent measurement error control group were taken as 1:2 ratio and comprised of 452 pregnant women.

\section{Study parameters}

- Maternal age

- Parity

- Gestational age

- Onset of labour

- Mode of delivery

- Grading of MSL

- FHR pattern

- Apgar score

- Length of NICU stay.

\section{RESULTS}

This case control study was conducted in the department of obstetrics and gynaecology, MGMCRI, Puducherry from January 2014 to July 2015. During this period pregnant women in labour who presented with meconium staining of amniotic fluid were compared with those with clear liquor.

Total numbers of deliveries during the study period of 18 months were 3420 . Of which 810 cases had meconium staining of amniotic fluid, which constituted to $23.6 \%$ of total deliveries (Table 1). Of these, only 226 cases that fulfilled the inclusion criteria were considered for study.

Table 1: Incidence of meconium stained amniotic fluid cases.

\begin{tabular}{|lll|}
\hline $\begin{array}{l}\text { No. of deliveries } \\
\text { during the period } \\
\text { of study } \\
\text { (n) }\end{array}$ & $\begin{array}{l}\text { No. of } \\
\text { meconium } \\
\text { stained cases }\end{array}$ & $\begin{array}{l}\text { Percentage of } \\
\text { meconium } \\
\text { stained cases } \\
(\%)\end{array}$ \\
\hline 3420 & 810 & 23.6 \\
\hline
\end{tabular}

In this study, $27 \%$ of deliveries had thin MSL and $63 \%$ cases had thick MSL (Table 2). 
Table 2: Type of meconium stained amniotic fluid in study group.

\begin{tabular}{|lll|}
\hline Amniotic fluid & No of cases $\mathbf{N}=\mathbf{2 2 6}$ & Percentage \\
\hline Thin MSL & 183 & $27 \%$ \\
\hline Thick MSL & 43 & $63 \%$ \\
\hline
\end{tabular}

There were no significant differences of gravidity in between meconium stained group and control group. In meconium stained group primigravida were $58.4 \%$ and in control group it was $57.4 \%$ cases (Figure 1 ).

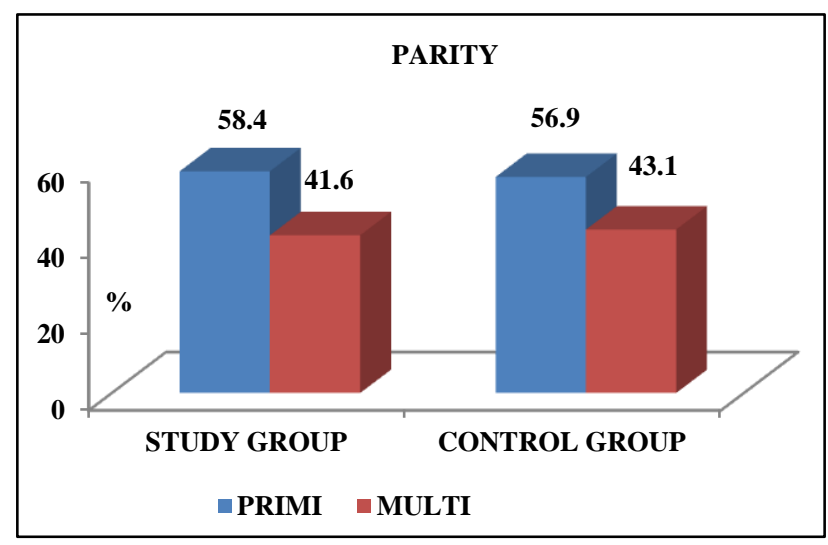

Figure 1: Parity distribution.

This table shows that post-dated cases are more (9\%) in meconium stained group compared to control group. Signifying that meconium passage is common occurrence in post-dated pregnancy. Mean gestational age in both study and control groups were also similar (Table 3).

Table 3: Gestational age.

\begin{tabular}{|lllll|}
\hline $\begin{array}{l}\text { Gestational age } \\
\text { (in weeks) }\end{array}$ & \multicolumn{2}{l|}{ Study $\mathbf{N}=\mathbf{2 2 6} 6$} & \multicolumn{2}{c|}{ Control $\mathbf{N}=\mathbf{4 5 2}$} \\
\hline 38 & 65 & 28.8 & 135 & 29.5 \\
\hline $39-40$ & 159 & 70.4 & 317 & 70.1 \\
\hline $41-42$ & 2 & 9 & 0 & 0 \\
\hline Mean \pm SD & $39.26 \pm 0.81$ & $39.2 \pm 0.73$ \\
\hline
\end{tabular}

$\mathrm{P}$ valve $=0.13$.

This table shows $47.8 \%$ cases had spontaneous labour in meconium staining group, whereas in control group it was $52.9 \%$ (Table 4).

Table 4: Onset of labour.

\begin{tabular}{|lllll|}
\hline Onset of labour & Study & \multicolumn{3}{c|}{ Control } \\
\cline { 2 - 5 } & $\mathbf{n = 2 2 6}$ & $\mathbf{\%}$ & $\mathbf{n = 4 5 2}$ & $\mathbf{\%}$ \\
\hline Induced & 118 & 52.2 & 213 & 47.1 \\
\hline Spontaneous & 108 & 47.8 & 239 & 52.9 \\
\hline $\mathrm{P}=0.45$. & & & & \\
\hline
\end{tabular}

Abnormal FHR was seen in $67.7 \%$ of new-borns in the study group but in the control group only $15.9 \%$ of the new-borns had abnormal FHR. This difference of NST reactivity was statistically significant with $\mathrm{P}=0.000$ (Figure 2).

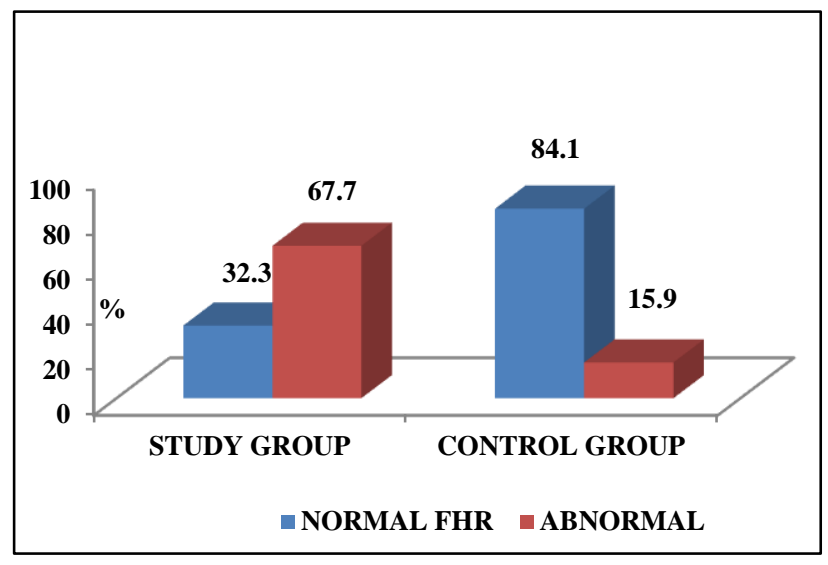

Figure 2: FHR pattern.

Thin meconium stained liquor was associated with $72.1 \%$ of abnormal FHR and thick meconium stained liquor was associated with $48.8 \%$ abnormal FHR patterns whereas in the presence of meconium, normal FHR was noted in $27.9 \%$ cases of thin MSL and $51.2 \%$ cases in thick MS (Table 5).

Table 5: FHR and grading of meconium.

\begin{tabular}{|lllll|}
\hline FHR & \multicolumn{2}{l}{ Thin MSL } & \multicolumn{2}{l|}{ Thick MSL } \\
\hline $\begin{array}{l}\text { No of } \\
\text { cases }\end{array}$ & $\%$ & $\begin{array}{l}\text { No of } \\
\text { cases }\end{array}$ & $\%$ \\
\hline Normal FHR & 51 & 27.9 & 22 & 51.2 \\
\hline Abnormal FHR & 132 & 72.1 & 21 & 48.8 \\
\hline P=0.000. & & & & \\
\hline
\end{tabular}

Incidence of CS was highest in study group (50.9\%), whereas $44 \%$ in control group which was statistically significant (Figure 3).

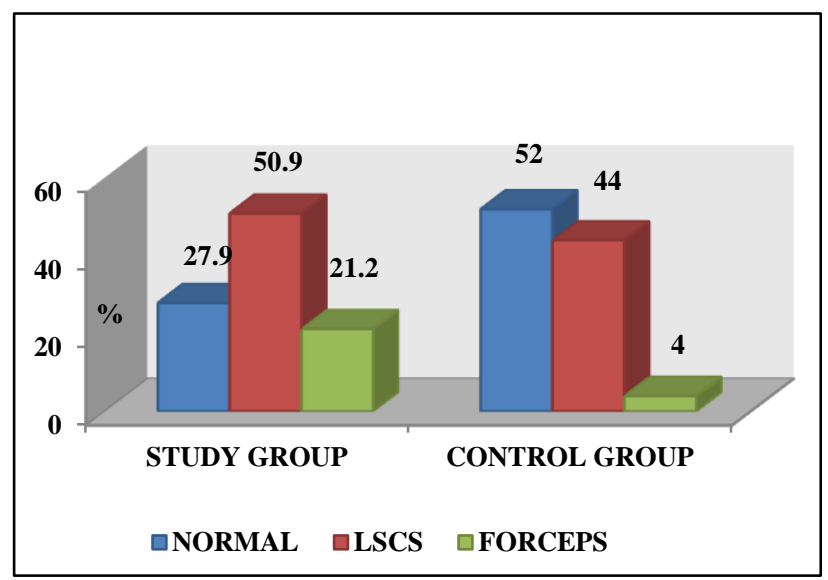

Figure 3: Mode of delivery.

This table shows that mode of delivery vary according to grading of meconium staining in study group. Incidence of CS was highest in thick group $(67.4 \%)$ compared to 
$47 \%$ in thin group whereas forceps deliveries were more in thin group (21.3\%) than thick group (20.9\%) (Table 6).

Table 6: Mode of delivery in MSL grading.

\begin{tabular}{|lllll|}
\hline $\begin{array}{l}\text { Mode of } \\
\text { delivery }\end{array}$ & Thick MSL & & Thin MSL & \\
\hline Normal & 5 & 11.6 & 58 & 31.7 \\
\hline LSCS & 29 & 67.4 & 86 & 47 \\
\hline Forceps & 9 & 20.9 & 39 & 21.3 \\
\hline P=0.000. & & & & \\
\hline
\end{tabular}

This table shows that $73.3 \%$ of cases of study group required NICU care of which thick meconium group about twice than that of thin meconium group. Only $16.7 \%$ of cases of control group were required NICU care (Figure 4).

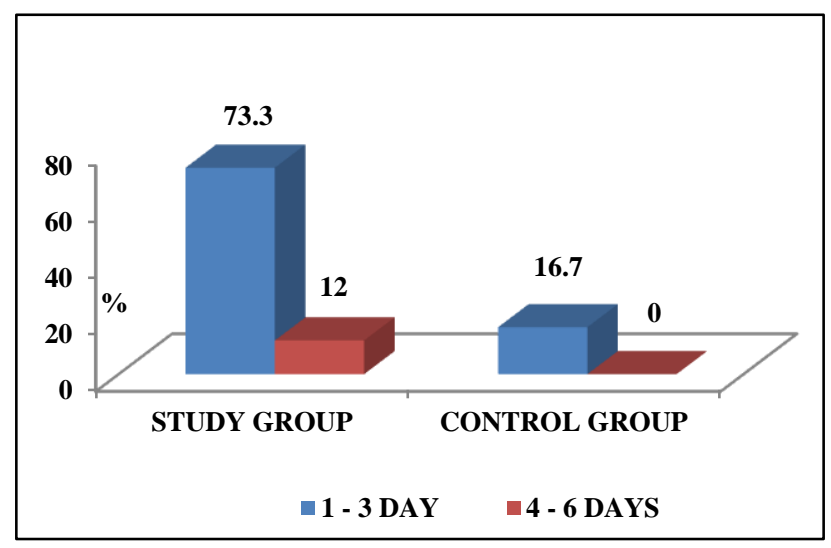

Figure 4: NICU admission.

Apgar score was $<7$ at 1 minute in $27.4 \%$ meconium stained group babies as compared to $7.5 \%$ babies in control group which was significant (Figure 5).

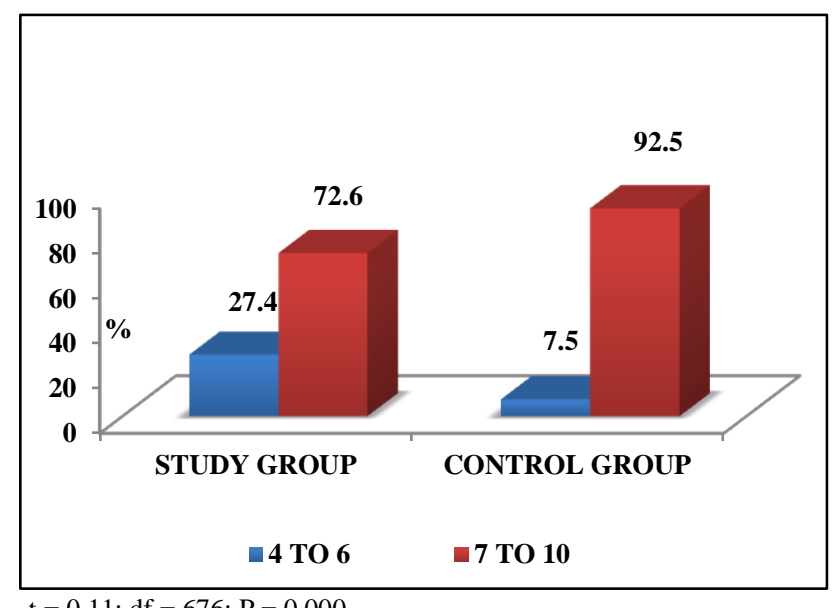

$\mathrm{t}=0.11 ; \mathrm{df}=676 ; \mathrm{P}=0.000$

Figure 5: Apgar score at 1 minute.

Apgar score was $<7$ at 5 minute in $10(4.4 \%)$ babies of study group as compared to $2 \%$ babies of control group (Figure 6).

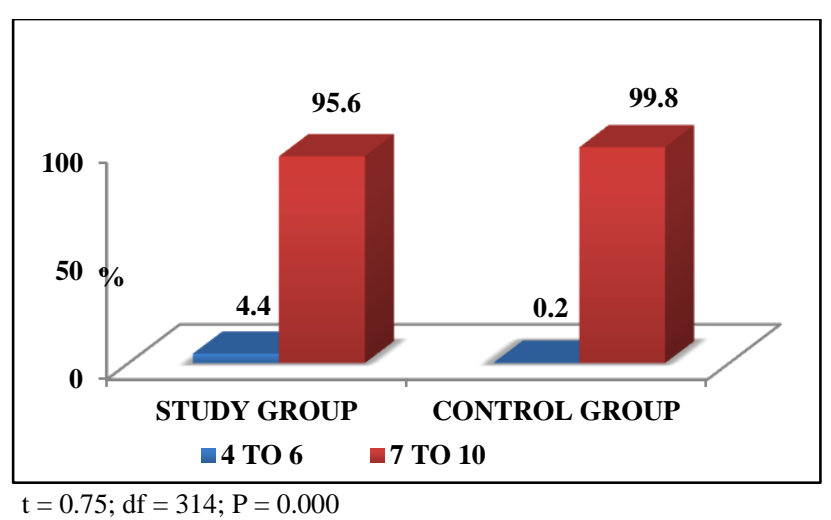

Figure 6: Apgar score at 5 minute.

In this study, $5.6 \%$ of thin meconium stained group babies were moderately asphyxiated at 1 minute whereas $3.5 \%$ babies were moderately asphyxiated in thick meconium stained group (Table 7).

Table 7: Apgar score at 1 minute in MSAF grading.

\begin{tabular}{|l|llll|}
\hline \multirow{2}{*}{ m minute } & Thin MSL & \multicolumn{1}{c}{ Thick MSL } \\
\cline { 2 - 5 } & No. of cases & \% & No. of cases & \% \\
\hline$<7$ & 38 & 5.6 & 24 & 3.5 \\
\hline$\geq 7$ & 145 & 21.4 & 19 & 2.8 \\
\hline$P=0.000$. & & & & \\
\hline
\end{tabular}

This table shows that $1.3 \%$ of babies in thick meconium stained group were moderately asphyxiated whereas $1 \%$ of babies in thin meconium stained group were moderately asphyxiated at 5 minutes (Table 8).

Table 8: Apgar score at 5 minute in MSL grading.

\begin{tabular}{|lllll|}
\hline \multirow{2}{*}{5 minutes } & Thin MSL & \multicolumn{3}{|c|}{ Thick MSL } \\
\cline { 2 - 5 } & No. of cases & $\%$ & No of cases & $\%$ \\
\hline$<7$ & 1 & 0.1 & 9 & 1.3 \\
\hline$\geq 7$ & 152 & 26.5 & 34 & 5 \\
\hline
\end{tabular}

\section{Meconium aspiration syndrome}

In this study, incidence of MAS was $1.3 \%$ (3) which was statistically significant $\mathrm{p}=0.000$.

\section{DISCUSSION}

Meconium stained amniotic fluid has been implicated as a fetal wellbeing during the intrapartum and postpartum periods. Presence of meconium in amniotic fluid in cephalic presentation was of greater concern even to midwives of old age. Whereas detection of meconium in breech presentation is insignificant as it was due to mechanical compression of fetal abdomen.

Presence of meconium in the amniotic fluid during labour often causes anxiety in delivery room because it is assumed as an indicator of poorfetal outcome. Fetal status 
during labour is usually assessed by measuring the fetal heart rate abnormalities and checking the colour of the amniotic fluid. It is often assumed that fetal heart rate abnormalities, especially in the presence of meconium stained liquor which indicates hypoxia and acidosis. ${ }^{7}$

Passage of meconium may be a normal physiological event reflecting fetal maturity. It also reflects fetal hypoxia or increased vagal activity from cord compression. The presence of meconium during labour is associated with an increased risk of perinatal mortality and morbidity. Most workers showed there is an association with fetal heart rate abnormalities, low Apgar scores and low arterial cord $\mathrm{PH}$ in the presence of meconium stained amniotic fluid. ${ }^{1}$

The present study was undertaken to evaluate the significance of meconium stained amniotic fluid and its fetal outcome inparturients admitted to Mahatma Gandhi Medical College and Research Institute between January 2014 to June 2015.

Out of 3420 deliveries conducted in our hospital during this period 678 cases were included in our study which fulfilled the inclusion criteria.

\section{Incidence}

As compared to others study incidence in the present study was higher. This may be attributed to more use of misoprostol as labour inducing agent (Table 9).

\section{Grading of MSAF}

In present study, among the study group, highest incidence was thin meconium compared to thick meconium stained amniotic fluid.

Out of 226 deliveries of our study period $27 \%$ cases had thin MSL and $6.3 \%$ of cases had thick MSL (Table 10).

Many authors found that incidence of thin MSL were high compared to thick MSL, which is comparable to our present study.

\section{Maternal age}

In the present study, maternal age found to be similar in study and control group whereas no other study commented about it.

\section{Gestational age}

Becker et al concluded from his work that frequency of meconium stained amniotic fluid is increases with advanced gestational age but in our study mean gestational age is 39 weeks in both study and control groups. $^{28}$
From Table 4, it is evident that $9 \%$ of mother in study group fall into the category of postdated pregnancy in comparison with control group. This proves that meconium passage is a common occurrence in post-dated pregnancy. Similar observation was also recorded by Miller where the incidence of postdated pregnancy was $30 \% 15$. In present studies it was $9 \%$. Mean gestational age was higher (39.8 weeks) in study group than control group (38.8weeks), whereas Rosario found mean gestational in study group was 39.6 weeks in comparison to control group (39.9 weeks). ${ }^{20}$

\section{MSAF and abnormal FHR}

In present study, abnormal FHR was found in $32.3 \%$ of study group and of $15.9 \%$ of control group.

Salma et al, from his work, found that non-reactive NST was observed in $28 \%$ cases of meconium stained cases compared to control group similarly, study by Patil et al showed that FHR abnormalities was seen in $56 \%$ of cases with MSAF. ${ }^{27,31}$ In present study, abnormal FHR was $32.3 \%$ of study group and $15.9 \%$ of control group.

Another study by Wong also evident that abnormal FHR was found in $9.4 \%$ cases of MSAF, while in the study by Naveen observed that $27 \%$ of cases of MSAF presented with fetal distress. All these results from various studies conclude that CTG abnormalities in MSAF as compared to control group which is similar to results of present study. $^{32}$

\section{Mode of delivery}

In present study incidence of CS was highest in thick MSL, that was $67.4 \%$ and out of 226 total meconium stained amniotic fluid cases $50 \%$ delivered by caesarean section whereas in control group it was $44 \%$ (Figure 3).

In comparison to thin MSL group incidence of caesarean section was near about double in thick MSL.

In comparison to thin MSL group incidence of caesarean section was near about double in thick MSL.

The main indication of CS in our study group was due to fetal distress detected by MSL associated with abnormal FHR.

\section{Parity}

From this study, meconium stained amniotic fluid is more commonly associated in primipara and results of this study are comparable with other studies (Table 12).

\section{APGAR score}

Surekha et al observed low Apgar score at 1 and 5 minutes and results were found statistically significant 
whereas Becker, from his study found there was no statistically significant difference in low Apgar scores. ${ }^{28}$

Low Apgar score in MSAF may be because of direct vasoconstrictor effect of meconium on umblical vein that results in vasospasm leading to impaired placental blood flow.

In study group 72.6\% babies had Apgar score 7-10 at 1 minute and 27.4\% babies had Apgar score of less than 6 in 1 minute while in control group $92.5 \%$ of cases had Apgar score of 7-10 at 1 minute and $7 \%$ cases had less than 7 (Figure 5).

In our study, 5 minutes Apgar score $>7$ was in $95.6 \%$ in study group compared to control group of $99.8 \%$ (Figure $6)$.

Only 4\% babies had Apgar score less than 6 at 5 minutes in study group (Figure 6).

\section{NICU care}

Present study showed that NICU care needed more in MSAF group babies than that of control group. Other study by Goud et al also observed 54\% of MSG babies required NICU care. ${ }^{5}$

Out of major complications among deliveries through MSAF, birth asphyxia was commonest complication.

Limitations of this study evident of fetal distress was not confirmed with fetal scalp PH or umbilical cord lactate.

\section{CONCLUSION}

The overall incidence of meconium staining of amniotic fluid during labour in our study was found to be $23.6 \%$. The incidence of meconium stained amniotic fluid was much greater in induced labour and post-dated pregnancy.

Abnormal FHR was much more frequent in study group. Thick meconium was associated with low Apgar score and meconium aspiration.

Operative interference was higher in pregnancy associated with MSL compared to control group.

$1 \mathrm{~min}$ and $5 \mathrm{~min}$ Apgar score was much lower in the pregnancy associated with MSL compared to control group and meconium staining of amniotic fluid had definitive predictive valve regarding low Apgar score and hence fetal outcome. NICU admission was higher in pregnancy associated with MSL compared to control group.

Incidence of MAS in our study was $1.3 \%$.
Funding: No funding sources

Conflict of interest: None declared

Ethical approval: The study was approved by the Institutional Ethics Committee

\section{REFERENCES}

1. Oyelese Y, Culin A, Ananth CV, Kaminsky LM, Vintzileos A, Smulian JC, et al. Meconium stained amniotic fluid across gestation and neonatal acid base status. Obstet Gynecol. 2006;108:345.

2. Fetaldistress. Am J Obstet Gynaecol. 1959;77:94107.

3. Yamada T, Minakami H, Matsubara S, Yatsuda T. Meconium stained amniotic fluid exhibits chemotactic activity for polymorphonuclear leukocytes in vitro. J Reprod Immunol. 2000;46:2130.

4. Paul J, Hall M, Marshall JR, Hobel CJ. Meconiumpassage: a new. 1978;31:509-13.

5. Goud P, Krishna U. Significance of meconium staining of amniotic fluid in labour. J Obstet and Gynaecol India. 1989;39:523-6.

6. Yoder BA, Kirsch EA, Barth WH, Gordon MC. Changing obstetric practices associated with decreasing incidence of meconium aspiration syndrome. J Obstet Gynecol. 2002;99:731-9.

7. Perinatology and contraception-Dutta DC. In: Konar $\mathrm{H}$, editor. Textbook of Obstetrics $.6^{\text {th }}$ ed. calcutta: New Central Book Agency (p) Ltd; 2004:256.

8. Rossi EM, Phillipson EH, Williams TG, kalhan SC. Meconium aspiration syndrome: intrapartum and neonatal attributes. Am J Obstet Gynaecol. 199810:107-10.

9. Wiswell TE, Gannon CM, Jacob J. Delivery room management of the apparently vigorous meconium stained neonates: results of the multicentre, international collaborative trial. J Paediatrics. 2000;105:1-7.

10. Abramovici H, Brandes JM, Fuchs K, Timor Tritsch I. Meconium during labour: a sign of compensated fetal distress. Am J Obstet Gynecol. 1974;118:251-5.

11. Tarnier BS, Losey RW, Bowes. Combined Obstetric and pediatric approach to prevent meconium aspiration syndrome. Am J Obstet Gynecol. 1969;126:111-8.

12. Wiswell TE, Henley MA. Intra-tracheal suctioning, systemic infection and the meconium aspiration syndrome. Paediatrics. 1992;89:203-6.

13. Jirasek JE, Uher J, Koldovysky O. A histochemical analysis of the development of the small intestine of human foetuses. 1965;22.

14. Desmond MM, Moore, Lindley JE. Meconium staining of the amniotic fluid - a marker for fetal hypoxia. J Obstet Gynaecol. 1957;9:91-103.

15. Millar FC, Sacks DA, Yeh SY, Paul RH, Schifrin BS, Martin. Significance of meconium during labour. Am J Obstet Gynaecol. 1975;122:573-80.

16. Sailing EW. Fetal scalp PH sampling. Arch Gynaecol. 1963;198:82-86. 
17. Spellacy WN, Buhi WC, Birk SA. Human placental lactogen levels and intrapartum fetal distress: meconium stained amniotic fluid, fetal heart rate patterns and Apgar scores. Am J Obstet Gynecol. 1972;114:803-80.

18. Steer PJ, Lissauer EF, Beard RW. Interrelationships among abnormal cardiotocography in labour, meconium staining of amniotic fluid, arterial cord blood PH and Apgar scores. Obstet Gynecol. 1989;74:715-21.

19. Hellman LM, Schiffer MA, Kohl SG, Tolkes V. Studies in fetal well-being; variations in fetal heart rate. Am J Obstet Gynecol. 1958;76:998-1012.

20. Rosario MC, Sheshadri L. Meconium staining of amniotic fluid in low risk parturients. J Obst Gynae India. 1996;46:642-6.

21. Nayak AH, Dalal AR. Meconium staining of amniotic fluid significance and fetal outcome. J Obstet Gynae. 1991;41:480-3.

22. Haribhasker S, Karthikeyan G, Bhat V, Bhatia BD. Antenatal risk factors and neonatal outcome in meconium aspiration syndrome. Indian $\mathrm{J}$ Mat $\mathrm{Ch}$ Health. 1997;8(1):9-12.

23. Sunoo CS, Kosasa TB, Nakayama RT, Hale RW. The incidence of meconium aspiration in Hawali. Hawali Med J. 1993;52:290-3.

24. Sedghatian MR, Otheman L, Rashid N, Ramachandran P. An 8 year study of meconium stained amniotic fluid in different ethnic groups. Kuwait Med J. 2004;36:266-9.

25. Fitzerald TB, Mc Farlane CN. Fetal distress and intrapartumfetal death. British Med J. 1955;2:35861.

26. Supriya. Thungasuchitra; clinical study of meconium stained amniotic fluid. Int $\mathrm{J}$ Bio Ad Res. 2014;5(12):610-4.

27. Naqvi SB, Manzoor S. Association of meconium stained amniotic fluid with perinatal outcome in pregnant women of 37-42 weeks gestation. Park J Surg. 2011;27(4):292-8.
28. Becker S, Solomayer E Dogan C, Wall wiener D, Fehm T. Meconium stained amniotic fluid perinatal outcome and obstetrical management in a low risk suburban population. Eur J Obstet Gynecol Reprod Biol. 2007; 132:46-50.

29. Khatun M. Meconium staining liquor and its correlative with fetal outcome within 7 days of birth in Dhaka medical college. Bangladesh college of physicians and surgeons; 2005:39-43.

30. Ara H, Arju J. Fetal outcome in deliveries with meconium stained liquor. Bangladesh J Child Health. 2009;33(2):41-5.

31. Patil KP, Swamy MK, Samatha K. A one year cross sectional study of management practices of meconium stained amniotic fluid and perinatal outcome. J Obst Gynecol India. 2006;56(2):128-30.

32. Kumar SV, Ritu S, Kushia P. Predictors of meconium stained amniotic fluid; a possible strategy to reduce neonatal morbidity and mortality. J Obstet Gynecol India. 2006;56(6):90-2.

33. Khatree $\mathrm{MH}$, Mokgokong ET. The significance of meconium staining of liquor amnii during labour. S A Fr Med J. 1979;56(25):1099-101.

34. Windle WF. Origin and extent of function of prenatal life, in physiology of the fetus. Philadelphia: WB Sounders Co. 1940(22):41-5.

35. Hobel CJ. Intrapartum clinical assessment of fetal distress. Am J Obstet Gynecol. 1971;110:336-42.

36. Gelfand SL, Fanaroff JM, Walsh MC. Meconium stained fluid approach to the mother and the baby. Pediatr Clin North Am. 2004;51(3):655-67.

37. Gupta V, Bhatia BD, Mishra OP. Meconium stained amniotic fluid: antenatal, intrapartum and neonatal attributes. Indian Paedi. 1996(33):293-8.

38. Trimmer KJ, Gilstrap LC. Meconium and Birth asphyxia. Am J Obstet Gynecol. 1991;85:1010-2.

39. In Ahrens W, Pigeot I (eds). Handbook of Epidemiology. Berlin, Springer. 2005;287-319.

40. Kumar N. Clinical study of effect of meconium stained amniotic fluid on fetal morbidity and mortality. J Obstet Gynecol India. 2006;43:142-8.

Cite this article as: Samiyappa DP, Ghose S, John LB, Samal R. Maternal and perinatal outcome in meconium stained amniotic fluid at term: a case control study. Int J Reprod Contracept Obstet Gynecol 2016;5:3404-10. 